\title{
UJI LAPANG MESIN PENGOLAHAN SAGU PRODUKSI BENGKEL PERMESINAN AGROINDUSTRI UNIVERSITAS PAPUA
}

\section{FIELD TEST OF SAGO PROCESSING MACHINE PRODUCED BY AGROINDUSTRY WORKSHOP OF PAPUA UNIVERSITY}

\author{
Darma $^{1 凶}$, Reniana $^{1}$, Moh. Arif Arbianto ${ }^{2}$ \\ ${ }^{1}$ Jurusan Teknologi Pertanian, Fakultas Teknologi Pertanian, Universitas Papua \\ ${ }^{2}$ BPTP Papua Barat, Manokwari \\ ${ }^{\otimes}$ Komunikasi Penulis, email: darmabond@gmail.com \\ DOI:http://dx.doi.org/10.23960/jtep-lv9i3.191-200
}

Naskah ini diterima pada 26 Maret 2020; revisi pada 27 Agustus 2020;

disetujui untuk dipublikasikan pada 28 Agustus 2020

\begin{abstract}
Papua and West Papua Province have the large potential of sago palm (Metroxylon sagu), however, until now the production and utilization is very low compared with its potential. This is because of most farmers in this area still use traditional method in processing sago. The traditional method is labour intensive and time consuming process. Sago farmers in this area still apply traditional ways to process sago starch due to the lack of processing machines. The objective of this research was to conduct field testing of sago processing machine produced by Agroindustry Machinery Workshop of Papua University. The machines that have been tested consist of cylinder type sago rasping machine and stirrer rotary blade sago starch extraction machine. The machine's performance under field condition was evaluated by measuring parameters (a) rasping capacity, (b) extraction capacity, (c) starch percentage, (d) starch yield and (e) starch loss in waste. Results showed that all parts of the machine are functioning properly and farmers can easily operate the machine. The performances of the machines under field condition were (a) rasping capacity 1,159.8 kg/hour, (b) extraction capacity $243.8 \mathrm{~kg} / \mathrm{hour}$, (c) starch percentage $38.26 \%$, (d) starch yield $93 \mathrm{~kg} /$ hour and (e) starch loss in waste $1.03 \%$.
\end{abstract}

Keywords: cylinder type, field test, rasping machine, sago processing, starch percentage

\begin{abstract}
ABSTRAK
Provinsi Papua dan Papua Barat memiliki potensi sagu (Metroxylon sagu) yang besar, namun sampai saat ini produksi dan pemanfaatan pati sagu masih sangat rendah dibandingkan dengan potensinya. Hal ini disebabkan karena sebagian besar masyarakat masih menggunakan cara tradisional untuk pengolahan sagu. Metode tradisional tersebut memerlukan waktu yang lama dan menguras tenaga yang besar. Masyarakat di di daerah ini masih menggunakan cara tradisional oleh karena keterbatasan peralatan mekanis. Untuk mengatasi masalah ini maka diperlukan adanya mesin pengolahan sagu yang harganya terjangkau oleh masyarakat petani sagu. Tujuan penelitian ini adalah uji lapang mesin pengolahan sagu hasil produksi bengkel Permesinan Agroindustri Universitas Papua. Mesin pengolahan sagu yang diuji terdiri dari mesin parut sagu tipe silinder dan mesin ekstraksi pati tipe stirrer rotary blade. Evaluasi kinerja mesin pada kondisi lapang dilakukan dengan mengukur parameter (a) kapasitas pemarutan, (b) kapasitas ekstraksi, (c) rendemen pati, (d) hasil pati dan (e) kehilangan pati pada ampas. Kinerja mesin pada kondisi lapang adalah (a) kapasitas pemarutan 1.159,8 kg/jam, (b) kapasitas ekstraksi 243,8 kg/ jam, (c) rendemen pati 38,26\%, (d) hasil pati $93 \mathrm{~kg} / \mathrm{jam}$ and (e) kehilangan pati pada ampas 1,03\%.
\end{abstract}

Kata Kunci: mesin pemarut sagu, pati sagu, pengolahan sagu, tipe silinder, uji lapang

\section{PENDAHULUAN}

Pengolahan sagu secara mekanis pada dasarnya sama dengan pengolahan secara manual, perbedannya hanya pada peralatan yang digunakan dan skala produksi. Prosedur pengolahan sagu adalah pemilihan pohon siap panen, penebangan pohon, penyiapan log untuk penghancuran empulur, yaitu pembersihan log, pemotongan dan pembelahan log, penghancuran empulur batang secara mekanik, ekstraksi pati, pengendapan pati, pengeringan pati segar, 
penggilingan, dan pengemasan. Pada pengolahan secara tradisional, produk akhir berupa pati segar/basah yang dikemas dalam kemasan yang terbuat dari anyaman daun sagu (tumang) untuk selanjutnya disimpan atau dijual. Pada pengolahan secara mekanis, produk akhir berupa pati sagu kering yang telah digiling yang dikemas dalam kemasan plastic atau karung. Pada pengolahan sagu secara tradisional, selain tidak efektif dan tidak efisien, pati yang dihasilkan juga berkualitas rendah. Sebaliknya, pada pengolahan sagu secara mekanis, tidak hanya lebih efektif dan lebih efisien namun juga menghasilkan pati yang berkualitas lebih tinggi dan lebih higienis (Karim et al., 2008; Singhal et al., 2008).

Pengolahan sagu oleh warga di Papua dan Papua Barat pada umumnya dilakukan secara tradisional oleh satu keluarga atau beberapa keluarga secara gotong royong. Jumlah anggota keluarga yang terlibat dalam kegiatan pengolahan sagu untuk setiap keluarga berkisar antara dua (2) sampai tiga (3) orang. Pada waktuwaktu tertentu, pengolahan dilakukan secara kelompok (gotong royong) dengan jumlah tenaga per kelompok 6 orang. Hasil olahan kemudian dijual secara bersama-sama dan hasil penjualannya dipergunakan untuk pembangunan fasilitas umum seperti pembangunan Gereja. Waktu yang diperlukan untuk mengolah 1 pohon untuk setiap keluarga adalah 6 hari dengan produksi pati basah ratarata $317 \mathrm{~kg} /$ pohon , atau setara dengan $52,8 \mathrm{~kg}$ / hari (Darma, 2006; 2011). Pada dekade terakhir ini, telah banyak warga di Papua dan Papua Barat yang melakukan pengolahan sagu secara semimekanis, bahkan di beberapa daerah telah menerapkan pengolahan secara mekanis walaupun masih dalam skala kecil.

Kampung Warbefondi merupakan salah satu desa di Distrik Supiori Selatan Kabupaten Supiori yang memiliki potensi sagu cukup tinggi, namun sebagian besar potensi tersebut tidak di manfaatkan. Banyak pohon sagu yang telah siap panen dibiarkan begitu saja di dusun sampai pohon mati. Hal ini disebabkan karena di Kampung Warbefondi khususnya dan Distrik Supiori Selatan pada umumnya masyarakat masih menerapkan teknik pengolahan secara tradisional. Pada pengolahan secara tradisional, tahapan yang membutuhkan waktu paling lama yaitu penghancuran empulur (penokokan) disusul ekstraksi (peremasan), sedangkan kegiatan lainnya curahan waktunya tidak begitu signifikan. Curahan waktu untuk proses penokokan dan peremasan berturut-turut 53,22 $\%$ dan 38,92 \% total waktu yang diperlukan untuk pengolahan. Hal tersebut menunjukkan bahwa sebagian besar waktu untuk pengolahan $(92,14 \%)$ tercurah untuk kedua proses ini (Darma, 2011). Oleh karena itu, perlu untuk merubah teknik pengolahan sagu secara tradisional ke pengolahan secara mekanis untuk meningkatkan pemanfaatan sumberdaya sagu yang ada. Untuk maksud tersebut tentunya diperlukan adanya sarana berupa mesin-mesin pengolahan yang sesuai dan mudah dioperasikan oleh masyarakat lokal. Penerapan teknologi pengolahan mekanis yang sesuai tentunya meningkatkan efisiensi produksi dan juga meringankan beban kerja petani sehingga diharapkan kesejahteraan petani pun meningkat.

Penerapan mesin pertanian di suatu lokasi harus memperhatikan aspek sosial dan budaya setempat agar tidak menemui kegagalan. Untuk maksud tersebut, setiap daerah diarahkan untuk mengembangkan mesin pertanian yang sesuai dengan kondisi wilayahnya. Pengembangan mekanisasi pertanian spesifik wilayah tentunya berdasarkan pada komoditi, kondisi tanah dan lahan, serta budaya spesifik lokal bersangkutan. Untuk maksud tersebut, Fakultas Teknologi Pertanian Uiversitas Papua telah mengembangkan mesin pengolahan sagu berupa mesin pemarut empulur batang dan mesin ekstraksi pati sagu. Mesin-mesin tersebut telah diuji kinerjanya dan bahkan telah digunakan di beberapa daerah yang pengadaannya baik secara pribadi maupun difasilitasi oleh pemda setempat.

Tujuan penelitian ini adalah uji lapang mesin mesin pengolahan sagu hasil produksi bengkel permesinan Agroindustri Universitas Papua. Mesin pengolahan yang diuji berupa mesin parut sagu tipe silinder variant-01 dan mesin ekstraksi pati sagu tipe stirrer rotary blade variant-01. Dari hasil penelitian ini akan diketahui kinerja mesin pada kondisi lapang atau kondisi yang operasional (real condition) sehingga dapat dijadikan dasar dalam penerapannya di suatu lokasi. 


\section{BAHAN DAN METODA}

Bahan-bahan yang digunakan pada penelitian ini ialah: pohon sagu siap panen, air bersih, bahan bakar bensin, papan, kayu balok dan terpal kedap air untuk pembuatan bak pengendapan pati. Peralatan yang digunakan yaitu mesin pemarut sagu tipe silinder variant-01 (menggunakan sistem pemarutan dengan pengupasan kulit batang), mesin ekstraksi pati sagu tipe stirrer rotary blade, (Darma et al., 2014), pompa air mitsumoto 1,5 inch, timbangan, stop watch, chain saw, ember, blender, saringan 100 mesh, parang, kampak dan kunci pas berbagai ukuran untuk setting dan perakitan mesin di tempat pengolahan.

Konstruksi dan pembuatan mesin pengolahan sagu dilaksanakan di bengkel Permesinan Agroindustri, Fakultas Teknologi Pertanian, Universitas Papua. Uji lapang dilakukan di Kampung Warbefondi, Distrik Supiori Selatan, Kabupaten Supiori, Provinsi Papua.

\subsection{Pelaksanaan Penelitian}

Penelitian ini terdiri dari dua tahap yaitu (1) Konstruksi dan pembuatan mesin pengolahan sagu dan (2) Pengujian lapang.

\subsubsection{Deskripsi Mesin Pengolahan Sagu yang Digunakan}

Mesin pengolahan sagu yang digunakan terdiri dari mesin pemarut empulur sagu tipe silinder bertenaga motor bakar (Darma et al, 2017; 2019) dan mesin pengekstrak pati sagu tipe stirrer rotary blade (Darma et.al., 2014; 2017) beserserta peralatan pendukung berupa pompa air dan bak pengendapan pati. Mesin pemarut sagu yang digunakan adalah tipe silinder variant01. Bagian fungsional (komponen proses) dari mesin pemarut ini berupa silinder terbuat dari kayu keras dan dibalut dengan plat stainless steel. Dengan berputarnya silinder yang telah diberi gigi potong berupa kawat stainless steel maka proses pemarutan akan berlangsung manakala diberikan input berupa empulur batang sagu. Pemarutan dilakukan dengan menempelkan dan mendorong bahan ke silinder parut yang sedang berputar. Mesin pemarut ini terdiri dari 5 bagian utama yaitu: (1) Rangka utama, (2) Tenaga penggerak (motor bakar bensin 5,5 hp), (3) Bagian pemasukan dan pengeluaran hasil parutan, (4) Silinder pemarut dan (5) Bagian transmisi daya. Bagian silinder pemarut diberi penutup pada bagian atas dan bagian bawah agar hasil parutan tidak terbuang. . Rangka utama terbuat dari besi siku berukuran $5 \mathrm{~cm}$ x $5 \mathrm{~cm}$ x $0.5 \mathrm{~cm}$. Bagian pemasukan dan pengeluaran bahan terbuat dari plat anti karat SS 304 tebal 2 $\mathrm{mm}$ yang pada ke-dua sisi ditekuk. Pengumpanan dilakukan dengan memasukkan empulur ke dalam pengumpan (hopper) lalu didorong dengan menggunakan tangan. Sistim transmisi yang digunakan berupa pulley dan VBelt (A2-50), untuk mengencangkan V-belt dilakukan dengan menggeser posisi motor ke depan atau ke belakang sebelum dikunci. Pada Tabel 1 ditampilkan deskripsi dan data teknis mesin pemarut sagu tipe silinder variant-01 yang digunakan pada penelitian ini.

Mesin ekstraksi pati sagu yang digunakan adalah tipe stirrer rotary blade. Komponen proses mesin ini berupa tabung ekstraksi bersirip yang dilengkapi dengan pengaduk dan penyaring pada dasar tabung. Bagian-bagian utama mesin ekstraksi ini adalah:(1) Tabung ekstraksi, terbuat daribahan plat baja anti karat SS 304 tebal $2 \mathrm{~mm}$ yang dibuat berbentuk tabung/silinder berdiameter $76 \mathrm{~cm}$, tinggi $120 \mathrm{~cm}$ dan pada dasar

Tabel 1. Data Teknis Mesin Pemarut Tipe Silinder Variant-01

\begin{tabular}{cll}
\hline 1. & Nama & $:$ Mesin Pemarut Sagu Tipe Silinder \\
\hline 2. & Dimensi (P x L x T $)$ & $: 56 \mathrm{~cm} \times 36 \mathrm{~cm} \times 33 \mathrm{~cm})$ \\
\hline 3. & Sistim pemarut & $:$ Dengan pengupasan kulit batang \\
\hline 4. & Komponen pemarut & $:$ Silinder bergerigi anti karat \\
\hline 5. & Transmisi & $: \mathrm{V}-$ Belt A-50 $(2 \mathrm{buah})$ \\
\hline 6. & Putaran Silinder parut & $: 2000-2700 \mathrm{rpm}$ \\
\hline 7. & Kapasitas parut & $: 800-1000 \mathrm{~kg}$ empulur sagu/jam \\
\hline 8. & Motor Penggerak & $:$ Honda GX $160,5.5 \mathrm{HP}$ \\
\hline 9. & Berat alat keseluruhan & $: 54 \mathrm{~kg}$ \\
\hline
\end{tabular}


silinder dibuat berbentuk kerucut untuk mencegah terjadinya endapan pati di dasar tabung, (2). Saringan, bahan dari plat anti karat (stainless stell SS 304) diameter lubang $1 \mathrm{~mm}$. Fungsi saringan ini untuk memisahkan suspensi pati dengan ampas, (3). Sirip turbulensi, terbuat dari baja strip anti karat, terdiri dari 12 sirip (blades) yang dipasang membentuk sudut tertentu pada dinding silinder bagian dalam Sirip ini berfungsi untuk menciptakan aliran turbulensi (eddy current) dari slurry sehingga pati lebih mudah terlepas dari ampas, dan juga agar tidak terjadi ruang kosong di tengah silinder akibat aliran berputar dari slurry, (4). Bilah pengaduk, dari bahan baja strip anti karat, terdiri dari 8 bilah horisontal dan 4 bilah vertikal. Penyusunan bilah diatur sedemikian rupa agar proses pengadukan berlangsung sempurna sehingga pelepasan pati berlangsung efektif, (5). Rangka utama, dari bahan besi siku ukuran $5 \mathrm{~cm}$ x $5 \mathrm{~cm}$ x 0,5 cm (SNI), (6). Motor Penggerak, berupa motor bakar honda 4 tak 6,5 HP.Bagianbagian lain dari mesin pengekstrak ini adalah : Gear box (WPX-80), saluran pengeluaran pati, dan bak penampung pati. Pada Tabel 2 ditampilkan deskripsi dan data teknis mesin ekstraksi pati sagu tipe stirrer rotary blade.

\subsubsection{Prosesedur Uji Lapang dan Analisis Data}

Bagan alir prosedur pengujian lapang ditampilkan pada Gambar 1.

\subsection{Variabel Pengamatan}

Parameter yang diukur untuk mengevaluasi kinerja mesin pada kondisi lapang adalah:

\section{a. Kapasitas pemarutan efektif}

Kapasitas pemarutan efektif yaitu kemampuan mesin parut untuk memarut/menghancurkan empulur batang sagu per satuan waktu tertentu, dihitung dengan menggunakan Persamaan 1.

$$
K P=\frac{E_{p}}{t}
$$

Dengan, $K P$ adalah kapasitas pemarutan efektif (kg/jam), me adalah massa empulur hasil parutan $(\mathrm{kg})$ dan $t$ adalah waktu pemarutan (jam).

\section{b. Kapasitas ekstraksi}

Kapasitas ekstraksi adalah kemampuan mesin ekstraksi untuk mengekstraksi pati per satuan waktu, diperoleh dengan menggunakan Persamaan 2.

$$
K E=\frac{H_{E}}{t}
$$

Dengan, $K E$ adalah kapasitas ekstraksi (kg/jam), $H_{E}$ adalah massa hancuran empulur batang (kg) dan $t$ adalah waktu ekstraksi (jam).

\section{c. Rendemen pati}

Rendemen pati adalah rasio/perbandingan massa pati hasil ekstraksi dengan massa empulur hasil parutan yang diproses. Rendemen pati diperoleh menggunakan Persamaan 3.

$$
R P=\frac{M_{P}}{H_{S}} * 100 \%
$$

Dengan, $R P$ adalah rendemen pati (\%), $M_{P}$ adalah massa pati $(\mathrm{kg})$ dan $H_{S}$ adalah massa hancuran empulur batang sagu (kg).

\section{d. Produksi pati}

Produksi pati basah adalah massa pati yang diperoleh dari proses pengolahan per satuan waktu (jam), ditimbang secara langsung dan/ atau menggunakan dengan menggunakan Persamaan 4.

\section{Tabel 2. Data Teknis Mesin Ekstraksi Pati Sagu Tipe Stirrer Rotary Blade}

\begin{tabular}{lll}
\hline 1. & Nama & $:$ Mesin ekstraksi pati sagu \\
\hline 2. & Dimensi alat $(\mathrm{P} \mathrm{x} \mathrm{L} \mathrm{x} \mathrm{T)}$ & $: 118 \mathrm{~cm} \times 90 \mathrm{~cm} \times 170 \mathrm{~cm}$ \\
\hline 3. & Dimensi Tabung $\varnothing \times \mathrm{T})$ & $: 76 \mathrm{~cm} \times 120 \mathrm{~cm}$ (volume: 544 liter $)$ \\
\hline 4. & Material Tabung & $:$ Stainless steel SS 304 \\
\hline 5. & Sistim Ekstraksi & $:$ Pengadukan dan Penyaringan \\
\hline 6. & Transmisi & $: \mathrm{V}-$ Belt A-83 $(2 \mathrm{buah})$ \\
\hline 7. & Putaran Pengaduk & $: 100 \mathrm{rpm}$ \\
\hline 8. & Kapasitas ekastraksi & $: 100 \mathrm{~kg}$ ela per proses $(300 \mathrm{~kg} / \mathrm{jam})$ \\
\hline 9. & Motor Penggerak & $:$ Honda GX 200, $6.5 \mathrm{HP}$ \\
\hline
\end{tabular}




$$
H P=K E * R P
$$

\section{e. Kehilangan pati terikut pada ampas}

Untuk mengetahui efektivitas proses ekstraksi, $1 \mathrm{~kg}$ sampel ampas (sago pith waste) diekstraksi ulang secara manual sampai air perasannya jernih (tidak ada lagi kandungan pati pada ampas). Pati yang dihasilkan ditimbang massanya dan kehilangan pati akibat terikut pada ampas diperoleh menggunakan Persamaan 5.

$$
P A=\frac{M P_{A}}{M S_{A}} * 100 \%
$$

Dengan, $P A$ adalah kehilangan pati akibat terikut pada ampas (\%), $M P_{A}$ adalah massa pati pada ampas (kg) dan $M S_{A}$ adalah massa ampas (kg).

\section{HASIL DAN PEMBAHASAN}

\subsection{Kapasitas Pemarutan Efektif}

Sebelum dilakukan pemarutan, terlebih dahulu log-log sagu di bawah ke tempat pengolahan (processing site). Log-log tersebut kemudian dikuliti dan dibelah-belah agar sesuai untuk proses pemarutan. Proses pemarutan dilakukan dengan menempelkan dan mendorong potongan empulur batang ke permukaan silinder pemarut (Gambar 2). Kapasitas pemarutan efektif disajikan pada Tabel 3.

Berdasarkan Tabel 3 terlihat bahwa rata-rata kapasitas pemarutan adalah $1.159,8 \mathrm{~kg} / \mathrm{jam}$. Hasil ini konsisten dengan hasil penelitian Darma et al. (2017 dan 2019), yang memperoleh kapasitas pemarutan efektif berturut-turut 1328 $\mathrm{kg} / \mathrm{jam}$ dan $1147 \mathrm{~kg} / \mathrm{jam}$. Namun demikian, kapasitas parut hasil penelitian ini lebih tinggi dibandingkan dengan hasil penelitian Reniana et al., (2017) dan Thoriq dan Sutejo (2017) yang menghasilkan kapasitas parut berturut-turut $322,52 \mathrm{~kg} / \mathrm{jam}$ dan $649,38 \mathrm{~kg} / \mathrm{jam}$. Hasil ini juga lebih tinggi dibandingkan dengan kapasitas pemarutan pada alat pemarut sejenis yang telah dihasilkan pada penelitian sebelumnya (Darma $2009 ; 2016 ; 2017 ; 2019$ ) yang memiliki kapasitas pemarutan efektif berturut-turut 635, 1009,603 dan $866 \mathrm{~kg} / \mathrm{jam}$. Hasil tersebut juga jauh lebih tinggi dibandingkan dengan kapasitas pemarutan alat pemarut sagu tipe piringan datar hasil rancangan Payung (2009) menggunakan

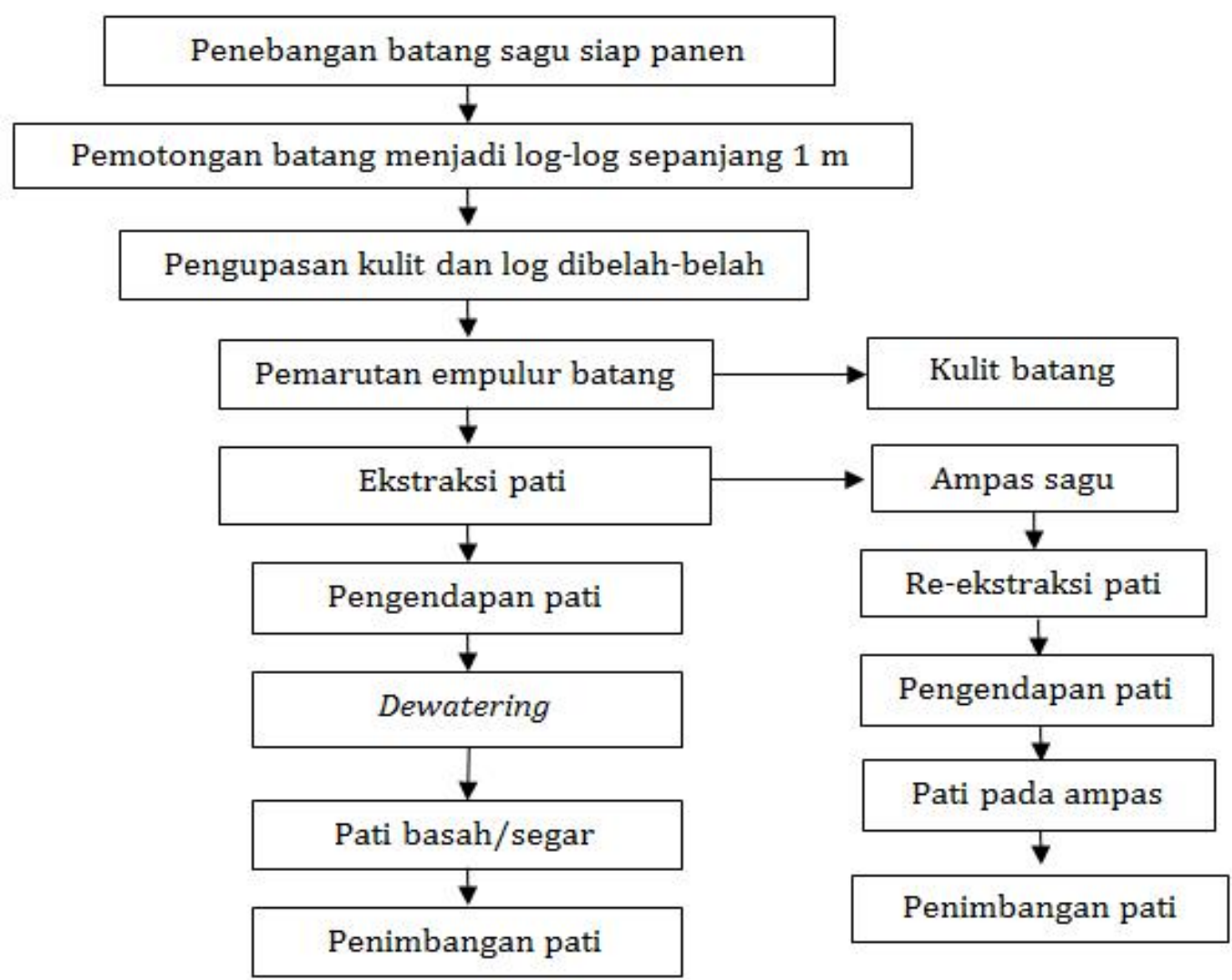

Gambar 1. Diagram Alir Proses Pengolahan Sagu Untuk Uji Lapang Mesin Pengolahan Sagu 
Tabel 3. Kapasitas Pemarutan Efektif Pada Pengolahan Sagu di Kampung Warbefondi

\begin{tabular}{cccc}
\hline Ulangan & $\begin{array}{c}\text { Waktu Pemarutan } \\
\text { (menit) }\end{array}$ & $\begin{array}{c}\text { Massa Empulur Hasil } \\
\text { Parutan (kg) }\end{array}$ & $\begin{array}{c}\text { Kapasitas Pemarutan } \\
\text { (kg/jam) }\end{array}$ \\
\hline 1 & 5 & 89,5 & 1.074 \\
2 & 5 & 78,3 & 939,6 \\
3 & 5 & 104 & 1.248 \\
4 & 10 & 184,5 & 1.107 \\
5 & 10 & 180,6 & $1.083,6$ \\
6 & 10 & 221 & 1.326 \\
7 & 15 & 230,3 & 921,2 \\
8 & 15 & 337,3 & $1.349,2$ \\
9 & 15 & 347,6 & $1.390,4$ \\
\hline Total & $\mathbf{9 0}$ & $\mathbf{1 7 7 3 , 1}$ & - \\
\hline Rata-rata & $\mathbf{1 2 0}$ & & $\mathbf{1 . 1 5 9 , 8}$ \\
\hline Manual ${ }^{*}$ & & $\mathbf{3 9}$ & $\mathbf{1 9 , 5 0}$ \\
\hline
\end{tabular}

${ }^{*}$ ): Penghancuran empulur sagu secara manual (tradisional) dilakukan dengan menggunakan alat penghancur yang oleh masyarakat papua pada umumnya disebut tokok, suatu alat sejenis palu. Pada pengujian ini, setiap pohon diambil sampel log sepanjang $1 \mathrm{~m}$ untuk diolah/dihancurkan secara manual oleh salah satu warga lokal yang telah berpengalaman.
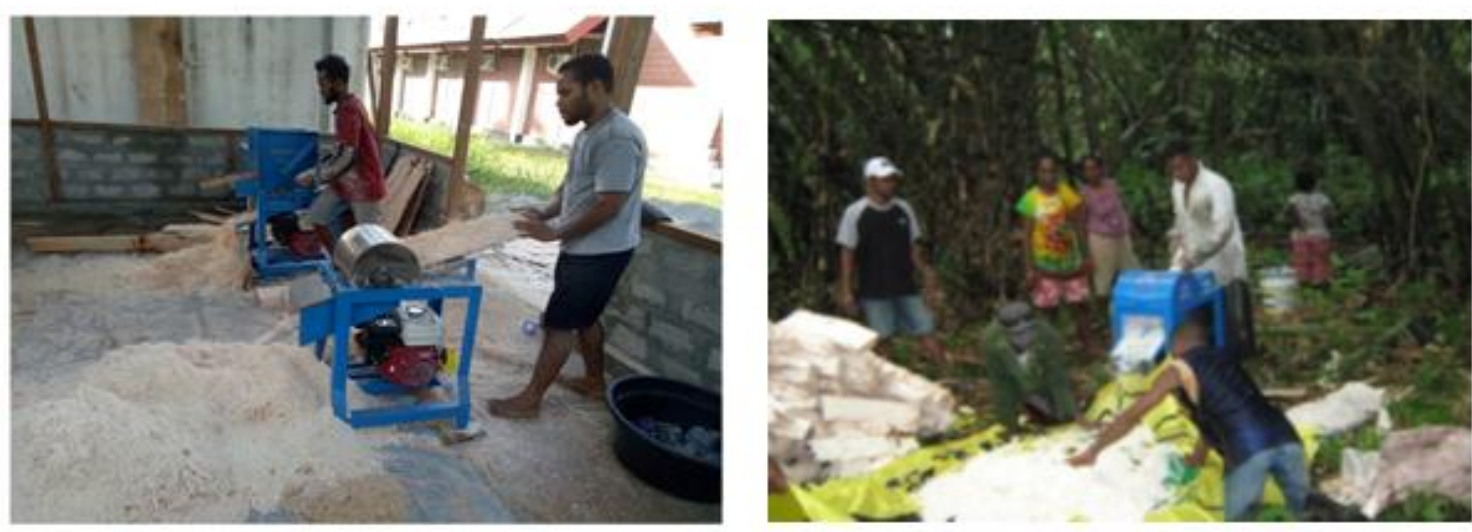

Gambar 2. Proses Pemarutan Empulur Batang Sagu

sumber tenaga penggerak $5,5 \mathrm{hp}$ dengan kapasitas pemarutan antara 108,817-131,153 $\mathrm{kg} / \mathrm{jam}$.

Pemarutan merupakan penghancuran bahan secara mekanik yang melibatkan proses pemotongan dengan menggunakan banyak mata potong (multiple blade). Untuk memperoleh pati semaksimum mungkin dari empulur sagu, penghancuran dilakukan sehalus mungkin (Colon dan Annokke,1984; Cecil, 1992). Pada dasarnya proses pemarutan bertujuan untuk merusak dinding sel agar pati yang terkandung di dalam sel dapat dipisahkan pada proses ekstraksi. Kapasitas pemarutan tergantung pada tipe alat, besarnya sumber tenaga penggerak, susunan gigi parut dan ketrampilan operator. Kapasitas pemarutan yang tinggi pada alat parut hasil pengembangan ini selain disebabkan karena pengaruh karakteristik gigi, juga karena rancangan hopper yang lebih sesuai sehingga memudahkan proses pemarutan.

Faktor lain yang mempengaruhi proses pemarutan adalah sifat mekanik bahan yang diproses. Menurut Sitkey (1986), sifat-sifat mekanik bahan tergantung pada tahap pertumbuhan (growing stage), kadar air dan posisinya dari arah pangkal atau dari arah ujung. Ketahanan pemotongan (cutting resistance) bagian tanaman yang lebih muda lebih rendah dari bagian tanaman yang lebih tua. Hal ini berhubungan dengan variasi tekstur sebagai akibat dari proporsi serat yang berbeda-beda menurut umur. Jadi tekstur dan ketahanan pemotongan (cutting resistance) fungsi dari umur. 
Kapasitas penghancuran empulur secara manual (tradisional), sebagaimana terlihat pada Tabel 3 adalah 19,5 kg/jam.Pada pengolahan sagu secara tradisional, tahapan proses dengan curahan waktu paling lama adalah penghancuran empulur (penokokan) disusul peremasan, sedangkan kegiatan lainnya curahan waktunya tidak begitu signifikan. Waktu yang diperlukan untuk penokokan adalah $53.22 \%$ dari total waktu yang diperlukan untuk pengolahan, dan $38.92 \%$ untuk peremasan. Dengan demikian sebagian besar waktu untuk pengolahan (92.14\%) tercurah untuk proses penokokan dan ekstraksi (Darma, 2011). Pengolahan sagu pada umumnya dilakukan oleh satu keluarga atau beberapa keluarga secara gotong royong. Banyaknya anggota keluarga yang terlibat dalam kegiatan pengolahan sagu tergantung dari banyaknya anggota keluarga yang sudah dewasa. Jumlah anggota keluarga yang terlibat dalam kegiatan pengolahan sagu untuk setiap keluarga berkisar antara dua sampai tiga orang dengan waktu pengolahan 6 hari untuk 1 pohon.

\subsection{Kapasitas Ekstraksi, Rendemen Pati, Hasil Pati dan Pati pada Ampas}

Proses ekstraksi diawali dengan memasukkan hancuran empulur batang sagu ke dalam tabung mesin ekstraksi kemudian mengalirkan suspensi pati ke bak pengendapan pati. Proses dihentikan manakala aliran suspensi/slurry dari tabung ekstraksi sudah tidak mengandung pati lagi. Mesin kemudian dihentikan dan ampas sagu dikeluarkan dari dalam tabung ekstraksi. Pada saat yang bersamaan, suspensi pati didiamkan beberapa saat dalam bak pengendapan hingga butiran pati mengendap. Pati lalu diambil untuk kemudian dikemas ditimbang massanya (Gambar 3). Pada Tabel 4 disajikan rendemen pati, hasil pati, kapasitas ekstraksi dan kehilangan pati terikut ke ampas.

Berdasarkan Tabel 4 terlihat bahwa kapasitas ekstraksi rata-rata $243,8 \mathrm{~kg} / \mathrm{jam}$ dengan waktu rata-rata per proses 28 menit. Hasil tersebut konsisten dengan hasil penelitian Darma et al., (2017) yang menghasilkan kapasitas ekstraksi $222 \mathrm{~kg} / \mathrm{jam}$, namun lebih tinggi dari hasil penelitian penelitian (Darma et al., 2010; 2014) yang memiliki kapasitas ekstraksi berturut-turut $120 \mathrm{~kg}$ ela per jam dan $209 \mathrm{~kg}$ per jam. Mesin ekstraksi yang digunakan adalah tipe batch, bukan kontinyu. Waktu yang diperlukan per batch (sekali proses) adalah 28 menit.

Tabel 4. juga memperlihatkan bahwa rendemen pati rata-rata adalah $38,26 \%$. Hasil ini sejalan dengan hasil penelitian Darma et al., (2014;

Table 4. Rendemen Pati, Hasil Pati, Kapasitas Ekstraksi dan Kehilangan Pati pada Ampas

\begin{tabular}{ccccccc}
\hline Ulangan & $\begin{array}{c}\text { Waktu } \\
\text { Ekstraksi } \\
\text { (menit) }\end{array}$ & $\begin{array}{c}\text { Massa Ela } \\
\text { (kg) }\end{array}$ & $\begin{array}{c}\text { Massa Pati } \\
\text { (kg) }\end{array}$ & $\begin{array}{c}\text { Rendemen } \\
\text { Pati (\%) }\end{array}$ & $\begin{array}{c}\text { Kapasitas } \\
\text { Ekstraksi } \\
\text { (kg/jam) }\end{array}$ & $\begin{array}{c}\text { Pati pada } \\
\text { Ampas } \\
\text { (\%) }\end{array}$ \\
\hline 1 & 24 & 89,5 & 33,5 & 37,43 & 223,7 & 0,97 \\
2 & 16 & 89,6 & 31,2 & 34,82 & 336,0 & 1,57 \\
3 & 17 & 89,6 & 29,6 & 33,03 & 316,2 & 0,96 \\
4 & 28 & 100,9 & 45,3 & 44,89 & 216,2 & 0,99 \\
5 & 22 & 100,5 & 31 & 30,84 & 274,9 & 1,04 \\
6 & 25 & 101,3 & 40,5 & 39,98 & 243,1 & 1,01 \\
7 & 36 & 120,2 & 56,1 & 46,67 & 200,3 & 1,01 \\
8 & 28 & 120,1 & 48,1 & 40,04 & 257,3 & 1,02 \\
9 & 28 & 120,6 & 49,1 & 40,71 & 258,4 & 0,97 \\
10 & 32 & 120,1 & 38,2 & 31,80 & 225,1 & 0,95 \\
11 & 32 & 120,1 & 47,1 & 39,21 & 225,1 & 0,96 \\
12 & 32 & 120,2 & 39,8 & 33,11 & 225,3 & 1.02 \\
13 & 32 & 120,2 & 41,3 & 34,35 & 225,3 & 1.06 \\
14 & 32 & 120,1 & 48,5 & 40,38 & 225,1 & 0,97 \\
15 & 32 & 120,2 & $\mathbf{5 2 , 6}$ & 43,76 & 225,3 & 0,99 \\
16 & 32 & 120 & 49,3 & 41,08 & 225 & 1,03 \\
\hline Total & $\mathbf{4 4 8}$ & $\mathbf{1 7 7 3 , 1}$ & $\mathbf{6 8 1 , 2}$ & - & - & - \\
\hline Rata-rata & $\mathbf{2 8}$ & - & - & $\mathbf{3 8 , 2 6}$ & $\mathbf{2 4 3 , 8}$ & $\mathbf{1 , 0 3}$ \\
\hline Tradisional & $\mathbf{1 2 0}$ & $\mathbf{8 0 , 5}$ & $\mathbf{2 6 , 3}$ & $\mathbf{3 2 , 6}$ & $\mathbf{4 0 , 2 5}$ & $\mathbf{4 , 1 1}$ \\
\hline
\end{tabular}



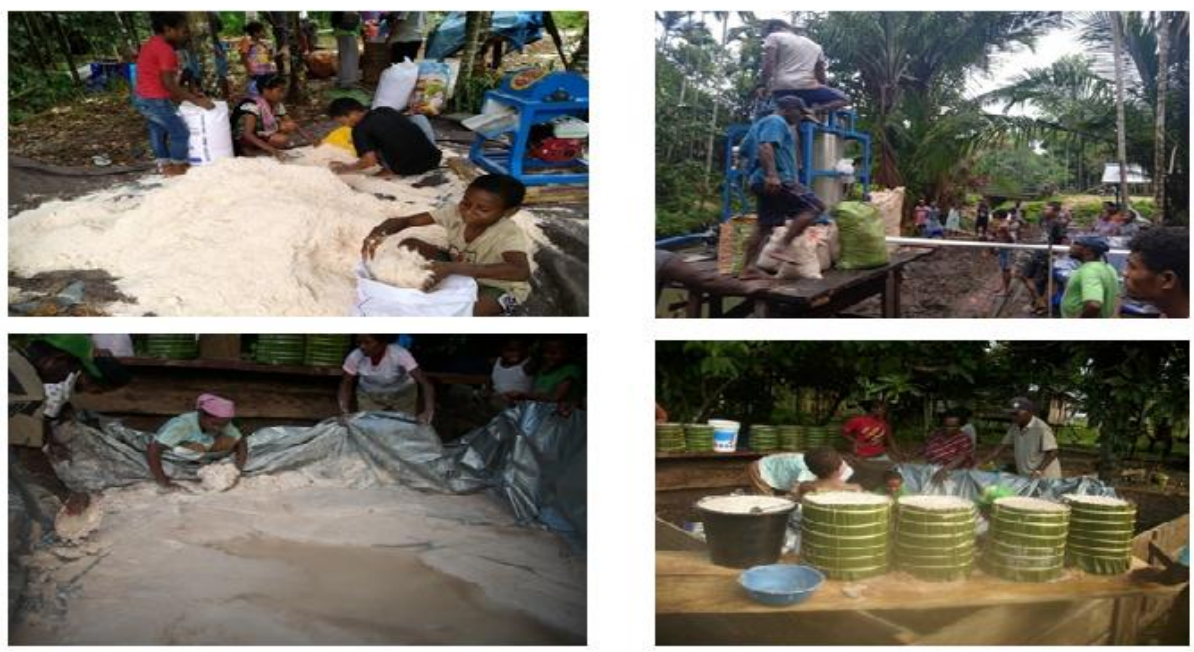

Gambar 4. Proses Ekstraksi Pati Sagu Menggunakan Mesin Ekstraksi Pati

2017) yang menghasilkan rendemen pati berturut turut $\quad 35.9 \%$ dan 40,5\%. Hasil ini juga konsisten dengan hasil penelitian Reniana et al., (2017) yang memperoleh rendemen pati $37,44 \%$.

Rendemen pati tidak hanya tergantung pada jenis dan umur sagu, namun juga pada teknik pengolahan. Darma (2011), melaporkan bahwa kandungan pati sagu di beberapa lokasi di Papua berkisar antara $12.43 \%-39.89 \%$ (rata-rata $26.85 \%$ ). Menurut Paulinus (2005), di Kabupaten Merauke ada jenis sagu dengan kandungan pati basah mencapai $56 \%$. Singhal et al., (2008) melaporkan bahwa kandungan pati pada pohon sagu siap panen bervariasi antara $18.8 \%$ sampai $38.8 \%$ (fresh weight basis).

Tabel 4 juga memperlihatkan bahwa produksi pati basah/pati segar (kadar air 46\%) adalah $707,5 \mathrm{~kg} / 2$ pohon atau setara dengan $353,75 \mathrm{~kg} /$ pohon. Dengan kapasitas ekstraksi rata-rata $243,8 \mathrm{~kg}$ per jam dan rendemen pati $38,26 \%$ berarti hasil/produksi pati per jam adalah 93 kg. Hasil ini lebih tinggi dari hasil penelitian Darma et al., (2015) di kampung Kaibi, Kabupaten Teluk Wondama yang menghasilkan produksi pati per pohon $287 \mathrm{~kg}$. Di daerah Papua dan Papua Barat, rata-rata produksi pati sagu segar adalah $317 \mathrm{~kg} /$ pohon (Darma, 2011). Hasil produksi pati oleh masyarakat setempat di kemas dalam anyaman daun sagu (tumang) dengan ukuran yang bervariasi. Pada waktu kegiatan ini berlangsung, pati dikemas dalam karung atau dalam wadah plastik untuk kemudian dijual. Kemasan dalam wadah plastik dan karung plastik bermassa antara $20 \mathrm{~kg}-23 \mathrm{~kg}$ dijual dengan harga Rp. 200.000 atau setara dengan Rp. 10.000/kg. Dengan produksi pati per pohon rata-rata $353,7 \mathrm{~kg}$, berarti jika dalam 1 minggu petani mengolah 6 pohon, maka produksi pati basah dalam seminggu adalah $2.122,5 \mathrm{~kg}(2,12$ ton $)$. Dengan demikian, kapasitas produksi meningkat 6 kali lipat jika dibandingkan dengan pengolahan yang dilakukan secara tradisional. Penggunaan alat mekanis ini disamping meningkatkan gairah kerja petani karena pekerjaan menokok yang merupakan pekerjaan terberat dalam proses pengolahan sagu tergantikan dengan mesin, juga mengurangi kehilangan pati yang terbuang bersama ampas.

Persentase pati yang terikut ke ampas (losses) rata-rata $1.03 \%$. Hasil penelitian Darma et al., (2017) memperoleh losses pati akibat terikut pada ampas 3,6\%. Jumlah kehilangan pati pada ampas yaitu sebesar 1,03\%, tergolong rendah dibandingkan dengan kehilangan pati terikut ke ampas pada pengolahan secara tradisional $(4,3$ \%). Hasil tersebut menunjukkan bahwa proses ekstraksi pati berlangsung efektif karena $99 \%$ pati terbebas (free starch) yang terdapat pada empulur berhasil diekstrak. Hal tersebut menunjukkan bahwa efektivitas mesin dalam memisahkan pati dari ampas adalah tinggi. Pada pengolahan sagu secara tradisional oleh masyarakat Papua dan Papua Barat, kehilangan pati pada ampas rata-rata 9.3\% (Darma, 2011). 


\section{KESIMPULAN DAN SARAN}

\subsection{Kesimpulan}

Mesin pengolahan sagu hasil produksi bengkel Permesinan Agroindustri Universitas Papua berfungsi baik dengan kinerja yang tinggi pada kondisi lapang. Kinerja mesin pada kondisi lapang adalah (a) Kapasitas pemarutan 1.159,8 kg/jam, (b) Kapasitas ekstraksi 243,8 kg/jam, (c) Rendemen pati 38,26\%, (d) Produksi pati $93 \mathrm{~kg} / \mathrm{jam}$ dan (e) Persentase kehilangan pati terikut ke ampas 1,03 \%. Kapasitas pengolahan adalah 1 pohon per hari dengan produksi pati basah 353,75 kg. Curahan waktu yang diperlukan untuk proses pemarutan dan mengekstraksi pati 1 pohon sagu dengan massa empulur batang $926,8 \mathrm{~kg}$ berturut-turut $0,8 \mathrm{jam}$ dan 3,8 jam.

\subsection{Saran}

Perlu dilakukan penelitian lebih lanjut untuk menganalisis kualitas pati dan analisis ekonomi untuk mengetahui tingkat kelayakan secara ekonomi dari mesin pengolahan pati sagu berupa mesin parut sagu tipe silinder bertenaga motor bakar dan mesin ekstraksi pati sagu tipe stirrer rotoary blade.

\section{UCAPAN TERIMA KASIH}

Penulis menyampaikan apresiasi dan terima kasih kepada Kementerian Riset, Teknologi dan Pendidikan Tinggi c.q. Direktorat Jenderal Penguatan Inovasi atas dukungan dana untuk penelitian ini melalui program CPPBT tahun anggaran 2018.

\section{DAFTAR PUSTAKA}

Cecil, J. E. 1992. Small-,medium-and large-scale starch Processing. Rome: FAO Agricultural Services Bulletin, 98.

Colon, F.J. and Annokke, G.J. 1984. Survey of Some Processing Route of Sago in: The expert consultation of the sago palm and palm products. BPP Teknologi \& FAO. Jakarta.

Darma, 2006. Small Scale Processing of Sago: An Alternative Solution to Optimize Sago Resources Utilization in Papua. In: Sago
Palm Development and Utilization. Proceeding of $8^{\text {th }}$ International Sago Symposium August 4 -6, 2005. Universitas Negeri Papua. Manokwari.

Darma. 2009. Prototipe Alat Pemarut Sagu Tipe Silinder Bertenaga Motor Bakar Bensin. Journal Agrotek, Publikasi Ilmu dan Teknologi Pertanian 1 (6) : x-y

Darma, Istalaksana, P., dan Gani, A. 2010. Prototype Alat Pengekstrak Pati Sagu Tipe Mixer Rotary Blade Bertenaga Motor Bakar. Agritech, 30 (4) :204-217.

Darma. 2011. Traditional Processing of Sago in Papua. In: Prooceedings of the $10^{\text {th }}$ International Sago Symposium: Sago for food security, Bio-energy, and Industry From Research to Market, October 29 30, 2011. Bogor Agricultural University.

Darma, Wang, X., Kito, K. 2014. Development of Cylinder Type Sago Rasper for Improving Rasping Performance. International Agricultural Engineering Journal (IAEA) 23(3) :31-40.

Darma, Wang, X., Kito, K. 2014. Development of Sago Starch Extractor with Stirrer Rotary Blade forImproving Extraction Performance. International Journal of Engineering and Technology (IJET) 6 (5) :2472-2481.

Darma dan Triyanto, B. 2015. Development and Performance Test of Cylinder Type Sago Rasper Powered by Petrol Engine. Prosiding Seminar Nasional PERTETA 5 - 7 Agustus, 2015. Universitas Hasanuddin. Makassar.

Darma dan Sumartono. 2015. Pemberdayaan dan Pengembangan Industri Pengolahan Pati Sagu Rakyat di Kabupaten Teluk Wondama, Papua Barat. Laporan Program Insentif Diseminasi Produk Teknologi ke Masyarakat. LPPM Unipa. Manokwari.

Darma dan Kurniawan, A. 2016. Effect of Cylinder Rotation Speed, Teeth Density and Engine Power Rate on Performance of 
Cylinder Type Sago Rasping Machine. in: The $1^{\text {st }}$ international conference : The role of agricultural engineering for sustainable agricultural production (AESAP). 13-14 Desember, 2016, IPB Bogor.

Darma, Santoso, B., dan Reniana. 2017. Development of cylinder type sago rasping machine using pointed teeth. International Journal of Engineering and Technology (IJET-IJENS) 17(1) : 2472-2481.

Darma, Santoso, B., Arbianto, M. A. 2019. Effect of Hopper Angle and Teeth Density on Performance of Cylinder Type Sago Rasping Machine. IOP Conf. Series: Earth and Environmental Sciences 355 : 012114.

Karim, A.A., Tie, P.L., Manan, D.M.A., and Zaidul, I.S.M. 2008. Starch from the sago (Metroxylon sagu) palm tree-properties, prospect, and challenges as a new industries source for food and other uses. Comprehensive Reviews in Food Science and Food Safety. Institute of Food Technology, 7 (3):215-228.
Paulinus, K. 2005. Studi Pengolahan Sagu Secara Tradisional di Kabupaten Merauke Papua. Skripsi. Fakultas Pertanian dan Teknologi Pertanian UNIPA. Manokwari.

Payung, P. 2009. Design and performance test of disc type sago rasper (Metroxylon sp). Agrotek Journal 1(4):32-37.

Reniana, Darma dan Kurniawan, A. 2017. Prototipe Mesin Parut Empulur Sagu Bertenaga Motor Bakar .Jurnal Teknik Pertanian Lampung 6 (2): 89-94.

Singhal, R.S., Kennedy, J.F., Gopalakrishnan, S.M., Kaczmarek, A., Knill, C.J., and Akmar, P.F. 2008. Industrial production-processing, and utilization of sago palm-derived products. Carbohydrate Polymers, 72(1) : 1-20.

Sitkey, G. 1986. Mechanics of Agricultural material. ELSEVIER. Amsterdam.

Thoriq, A. dan Sutejo, A. 2017. Desain dan Uji Kinerja Mesin Pemarut Sagu Tipe TPB 01. Agritech 37 (4): 453-461. 